\title{
Intraluminal duodenal "windsock" diverticulum; Case Report and discussion
}

\author{
Salem Asselhab, Malik Alkhanfas, Mahdi Alsakloul, Maryam Abuojaylah, Ibrahim Altomi. \\ Department of surgery, Sebha Medical Center, Sebha, Libya. \\ Corresponding Email: mahdialsakloul@gmail.com
}

\begin{abstract}
Intraluminal duodenal diverticulum (IDD) is a rare developmental anomaly usually found in the second portion of the duodenum. The cause appears to be a failure of recanalization of the occluded foregut lumen of the human embryo, resulting in a fenestrated mucosal membrane [1]. A small aperture in this diaphragm will gradually cause it to elongate caudally in response to duodenal peristalsis to form the so called "wind-sock" configuration. Symptoms are nonspecific and generally depend on the degree of duodenal obstruction; $25 \%$ of cases are associated with GI bleeding. In most documented cases, IDD was diagnosed radiologically, but the value of endoscopy for diagnosis and treatment has been amply demonstrated.
\end{abstract}

Keywords: Diverticulum; Duodenal Diseases;

Citation.Asselhab S, Alkhanfas M, Alsakloul M, Abuojaylah M, Altomi I.Intraluminal duodenal "windsock" diverticulum; Case Report and discussion.Libya J Med Res. 2021;15(2):3-6https://doi.org/10.54361/ljmr.15202 Received:15/09/21; accepted: 14/10/21; published: 31/12/21

Copyright CLibyan Journal of Medical Research (LMMR) 2021. Open Access. Some rights reserved. This work is available under the CC BY license https://creativecommons.org/licenses/by-nc-sa/3.0/igo

\section{INTRODUCTION}

An intraluminal duodenal diverticulum (IDD) is a true diverticulum, the pathogenesis involves incomplete recanalization of the embryologic foregut in the 8th week of gestation [1]. Innormal development, there is initially hyperplasia of the epithelial cells of the duodenal mucosa that results in occlusion of the lumen. As a result of years of peristaltic

\section{CASE REPORT:}

A 67-year-old male, diabetic patient was admitted to the surgical ward with a history of epigastric pain and recurrent vomiting, revealed serum urea $114 \mathrm{mg} / \mathrm{dl}$, creatinine $2.0 \mathrm{mg} / \mathrm{dl}$, FBS $169 \mathrm{mg} / \mathrm{dl}$, otherwise all laboratory results were within normal range. forces, there is progressive ballooning of the tissue to form a pulsion-type diverticulum. For this reason, the median time of presentation is the fourth decade of life. The site of attachment is almost always in the second part of the duodenum, just distal to the ampulla of Vater[2].

early satiety and postprandial fullness for the last two weeks. He had significant weight loss, but no hematemesis, melena or dysphagia. Abdominal examination was unremarkable except for mild epigastric tenderness. Blood biochemistry

Abdominal ultrasound examination revealed marked distension of the stomach and pyloric 
thickening. Upper gastrointestinal endoscopy revealed dilated stomach with gastric outlet obstruction, normal mucosa of the first part of the duodenum and an intraluminal mass obstructing the second part of the duodenum with difficulty to pass the scope beyond. Contrast enhanced CT scan of abdomen showed well-defined low density mass, 52X39 $\mathrm{mm}$, seen in the second part of duodenum, with contrast revealing peripheral enhancement semi-sold content [Figure 2], suggestive of cystic benign tumor.

At laparotomy, kocherization of the duodenum and an enterotomy of the first part of the duodenum revealed an intraluminal duodenal cystic lesion [Figure 1] confirmed by aspiration of a brown content, which measured about $4 \times 3 \mathrm{~cm}$, located on the

\section{DISCUSSION}

Duodenal diverticula are common abnormalities seen in $12-27 \%$ of endoscopic [1] and $1-6 \%$ of upper gastrointestinal contrast studies [2]. Duodenal diverticula are classified into extra- or intraluminal. The exact mechanism of the development of the rare intraluminal duodenal diverticula is unknown. Most authors believe they are congenital abnormalities. Successful recanalization of the solid duodenum during human development can be impaired and initial membranous web-like lesions may elongate during adulthood, creating a pulsiontype intraluminal diverticulum $[3,4]$. These lesions typically remain asymptomatic. While is attached to the GI tract and is formed by only 2 layers of the duodenal mucosa.

\section{CONCLUSION}

Surgical diverticulectomy has traditionally been the treatment of choice[1-3]. However, based on multiple case reports, endoscopic diverticulectomy is an emerging alternative [12,13]. The optimal endoscopic approach has lateral border of the second part of the duodenum. In manipulation, it was blindended and covered with all layers of the bowel, and no further communication with the adjacent pancreas or common bile duct was identified. The protruding structure and the cyst in the duodenum were excised completely and specimen sent for histopathology. After this, we primarily closed the lining defect with a 2-0 Vicryl one-layer simple suture and a gastrojejunostomy were constructed. Histopathological examination elicited a true duodenal diverticulum.

2 months after surgery on follow up patient appears to gain weight and in better general condition. An upper endoscopy revealed a normal duodenum without apparent pathology.

some IDD lesions give rise to complaints such as bloating, nausea, vomiting, and abdominal pain, most cases are asymptomatic [2,4,5].

Typically, patients may experience weight loss due to discomfort associated with eating [4]. Common complications of IDD are partial bowel obstruction, bleeding secondary to ulceration, and, rarely, pancreatitis due to intermittent blocking of the ampulla of Vater[3,6-8]. In evaluating patients with such symptoms, the differential diagnosis includes a distal choledochocele, periampullary cystic mass, and duodenal duplication cyst.4,6 Unlike an IDD that is structurally continuous with the duodenal lumen, a duplication cyst

yet to be determined, although various techniques using a needle-knife and snares have been described [7,12-14]. The greatest potential benefit to patients is that endoscopic intervention affords a faster 
recovery time than standard surgery, although the paucity of outcomes data is of concern [7]. Further evaluation of such

\section{FIGURES}

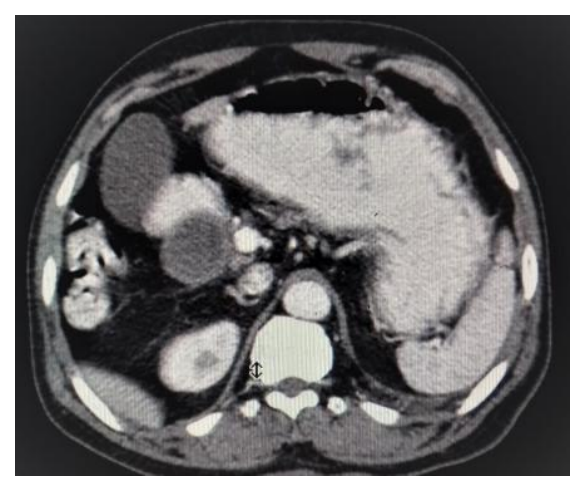

Figure 1 enterotomy of the first part of the duodenum revealed an intraluminal duodenal cystic lesion.

Figure 2 well-defined low density mass, $52 \times 39 \mathrm{~mm}$, seen in the second part of endoscopic procedures is warranted, particularly in regards to long-term outcomes.

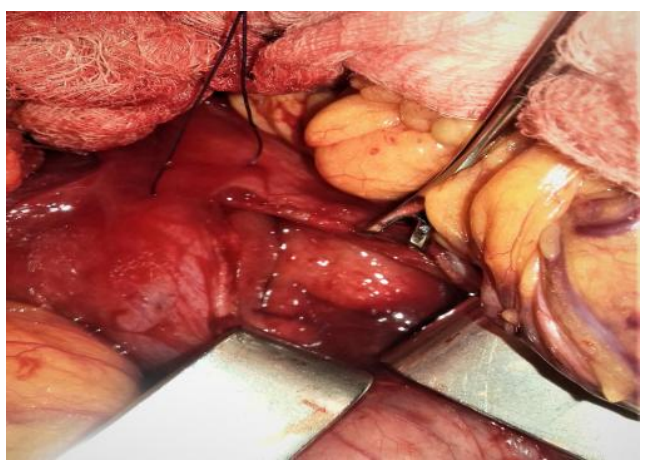

duodenum, with contrast revealing peripheral enhancement semi-sold content.

\section{Disclaimer}

The article has not been previously presented or published, and is not part of a thesis project.

\section{Conflict of Interest}

There are no financial, personal, or professional conflicts of interest to declare.

\section{REFERENCES}

1.Bargon, G.: AngebroeneMembranstenosen in

BeimErwachsenenmitIntraduodenaler (Intraluminarer) Pseudodiverticikelbildung. Fortschr. Geb. Roentgenstr. Nuklearmed., 100:319, 1964.

2.Coors, G. A. and Mitchum, W. R.: Intraluminal Duodenal Diverticulum. Am. J. Surg., 103:400, 1962.

3.Meyer, A. G., and Edgren, D. C.: Duodenal Obstruction by an Intraluminal Diverticulum. Arch. Surg., 103:1, 1956.
4.Zatzkin, H. R., Macy, J. J., Kveton, F. W.: Intraluminal Duodenal Diverticulum: Report of a Case: Am. J. Roentgenol. Radium Ther. Nucl. Med., 103:326, 1968.

5.Zoepf T, Zoepf DS, Arnold JC, Benz C, Riemann JF. The relationship between juxtapapillary duodenal diverticula and disorders of the biliopancreatic system: analysis of $350 \quad$ patients. GastrointestEndoscop2001;54:56-61 6. D’Alessio MJ, Rana A, Martin JA, Moser AJ. Surgical management of intraluminal 
duodenal diverticulum and coexisting anomalies. J Am Coll Surg 2005;201:143-148

7.Coors, G. A., and W. R. Mitchum. 1962. Intraluminal duodenal diverticulum. Amer. J . Roentgen. 103: 400402.

8. Nelson, W. 1. 1947. Congenital diaphragm of the duodenum. Case report with preoperative x-ray studies. Minnesota Med. 30: 745-742.

9. Lorente S, Lanas A, Aznar C, Jiménez E, Lozano R. Recurrentdigestive hemorrhage as a complication of an intraduodenaldiverticulum. Gastroenterol Hepatol. 1999;22:282---5.

10. Harthun NL, Morse JH, Shaffer HA et al: Duodenal obstruction caused by intraluminal duodenal diverticulum and annular pancreas in an adult. GastrointestEndosc 2002; 55:940943

11. Van Os EC, Petersen BT, Kelly DG et al: Endoscopic management of an intraluminal duodenal diverticulum. GastrointestEndosc 1996; 44:494-497.

12. Willemer S, Hans D, Johann FB, Rudolf A. Recurrent acute pancreatitis and intraluminal duodenal diverticulum. Pancreas. 1992;7:257-61.

13. Clemente G, G Gerardo ADR, Nuzzo G. Intramural duodenal diverticulum mimicking a periampullary neoplasm. Am J Surg. 2008;196:31-2.

14.Mathieu B, Salducci J, Remacle J-P, Pin G, Monges $\quad \mathrm{H}$. Intraluminalduodenal diverticulum. Am J Dig Dis. 1978;23:S1---5. 